\title{
A Simple Pseudo-Homogeneous Reversible Kinetic Model for the Esterification of Different Fatty Acids with Methanol in the Presence of Amberlyst-15
}

\author{
Mauro Banchero * (D) and Giuseppe Gozzelino \\ Department of Applied Science and Technology, Politecnico di Torino, Corso Duca degli Abruzzi, 24, \\ 10129 Torino, Italy; giuseppe.gozzelino@polito.it \\ * Correspondence: mauro.banchero@polito.it; Tel.: +39-011-090-4703
}

Received: 14 June 2018; Accepted: 12 July 2018; Published: 13 July 2018

\begin{abstract}
Fatty acid esterification with alcohols is a crucial step in biodiesel synthesis. Biodiesel consists of long-chain alkyl esters that derive from the transesterification or hydro-esterification of the triglycerides that are contained in vegetable oils. In the first route, the esterification of the free fatty acids is an important pretreatment of the feed; in the second, it is the main reaction of the industrial process. Knowledge of appropriate kinetic models for the catalytic esterification of fatty acids with alcohols is critical in the design of biodiesel synthesis processes. In this work, the kinetic behavior of the reversible esterification of lauric, myristic, palmitic and stearic acid, which are the most common saturated fatty acids that are contained in triglyceride feedstocks for biodiesel, with methanol at different temperatures $\left(70-150{ }^{\circ} \mathrm{C}\right)$ and molar ratios of the reactants (1:1-1:2-1:5) was investigated in a batch laboratory basket reactor both in the presence and absence of Amberlyst-15 as the catalyst. Results obtained with Amberlyst- 15 were fitted through a ready-to-use pseudo-homogeneous reversible model suitable for process design. The kinetic model was compared with that obtained in a previous work with niobium oxide as the catalyst. With respect to the results that were obtained with niobium oxide, the influence of the chain length of the acid on the kinetic behavior was strongly reduced in the presence of Amberlyst-15. This phenomenon was ascribed to a different catalytic mechanism.
\end{abstract}

Keywords: sulfonated cation-exchange resins; acid heterogeneous catalyst; free-fatty-acid (FFA) esterification; biodiesel production; pseudo-homogeneous reversible kinetics

\section{Introduction}

The esterification of organic carboxylic acids with alcohols, which is a useful synthesis reaction of organic esters for many industrial applications, has recently gained more attention since long-chain esters can be used as biofuels [1]. The biodiesel, which is a mixture of esters of fatty acids, can be obtained by transesterification or hydro-esterification of the triglycerides that are contained in vegetable oils or fats $[2,3]$.

The "transesterification-route" (Figure 1a) is the alcoholic transesterification of the triglycerides to obtain glycerol and the organic esters. It suffers the drawback of a high sensitivity to the free-fatty-acid (FFA) content of the oil feedstock since small amounts of FFAs result in soap formation, elevated catalyst consumption, and drastic reduction of the ester yield [4,5]. For this reason, the esterification of FFAs in the oil feedstock (Figure $1 b$ ) is performed as a pretreatment step to reduce the FFA content below $1-2 \%$, so avoiding the above-cited drawbacks [6].

The "hydro-esterification-route" (Figure 2) has been proposed as an alternative to the conventional transesterification one [4] to overcome the above-cited FFA pretreatment step, which is particularly 
expensive when non-traditional feedstocks, such as waste cooking oils and non-edible oils, are employed. These, in fact, are renewable "low-quality" bio-oils that contain a large amount of FFAs $[7,8]$. The hydro-esterification process consists of two steps: the non-catalytic hydrolysis of the unpurified oil to form FFAs (Figure 2a), which are subsequently esterified with an alcohol and the help of an acid catalyst to produce biodiesel (Figure $2 b$ ). Since all of the bio-oil is transformed into fatty acid intermediates during the hydrolysis stage, the presence of a high FFA content in the feedstock does not interfere with the overall reaction [3]. Furthermore, there is no contamination of biodiesel with the hydrolysis-by-product glycerol, which is easily removed in the hydrolysis step [4].

(a)

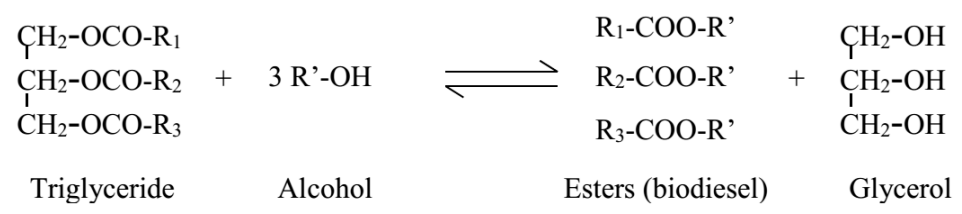

(b)

$\begin{array}{cccc}\mathrm{R}-\mathrm{COOH}+ & \mathrm{R}^{\prime}-\mathrm{OH} & \text { R-COO-R } & +\quad \mathrm{H}_{2} \mathrm{O} \\ \text { Free fatty acid } & \text { Alcohol } & \text { Ester (biodiesel) } & \text { Water }\end{array}$

Figure 1. Mechanism of the "transesterification-route": (a) transesterification reaction between triglyceride and alcohol to produce esters and glycerol; (b) esterification of free-fatty-acid (FFA), and alcohol to produce ester and water.

(a)

\begin{tabular}{|c|c|c|c|c|c|}
\hline $\mathrm{CH}_{2}-\mathrm{OCO}-\mathrm{R}_{1}$ & & & $\mathrm{R}_{1}-\mathrm{COOH}$ & & $\mathrm{CH}_{2}-\mathrm{OH}$ \\
\hline$\underset{1}{\mathrm{C}} \mathrm{H}_{2}-\mathrm{OCO}-\mathrm{R}_{2}$ & $+3 \mathrm{H}_{2} \mathrm{O}$ & $\rightleftharpoons$ & $\mathrm{R}_{2}-\mathrm{COOH}$ & + & $\underset{1}{\mathrm{C}} \mathrm{H}_{2}-\mathrm{OH}$ \\
\hline $\mathrm{CH}_{2}-\mathrm{OCO}-\mathrm{R}_{3}$ & & & $\mathrm{R}_{3}-\mathrm{COOH}$ & & $\mathrm{CH}_{2}-\mathrm{OH}$ \\
\hline Triglyceride & Water & & Fatty acids & & Glycerol \\
\hline
\end{tabular}

(b)

$\begin{array}{llll}\mathrm{R}-\mathrm{COOH}+ & \mathrm{R}^{\prime}-\mathrm{OH} & \text { R-COO-R' } & +\mathrm{H}_{2} \mathrm{O} \\ \text { Fatty acid } & \text { Alcohol } & \text { Ester (biodiesel) } & \text { Water }\end{array}$

Figure 2. Mechanism of the "hydro-esterification-route": (a) hydrolysis of triglyceride to produce FFA and glycerol; and (b) esterification of FFA and alcohol to produce ester and water.

The above discussion clearly points out that fatty acid esterification with alcohols plays a crucial role in the biodiesel synthesis, regardless of the route that was adopted for its production. In particular, while in the "transesterification route" the FFA esterification may be considered only a pretreatment step with not so a significant impact on the process as a whole, in the "hydro-esterification route" it is the main reaction of the industrial process. The knowledge of appropriate kinetic models for the catalytic esterification of fatty acids, then, becomes an important tool in the design of biodiesel production processes.

As far as biodiesel production is concerned, methanol is the most employed alcohol for the esterification of fatty acids, which is an equilibrium-limited, slow reaction that occurs in the liquid phase. The use of highly-active heterogeneous catalysts is particularly appealing for the chemical industry to avoid the corrosion and separation problems that were observed in the homogeneous catalysis with strong acids, either organic or inorganic [9]. For these reasons, many heterogeneous 
catalysts, such as enzymes [10], tungstated zirconia [11], niobium oxide [12], and zeolites [3] have been proposed in the literature. In addition, the use of resin-supported strong solid acids is under continuous development aiming at a more efficient overall production of biodiesel from biomass feedstocks with high FFA content as it has been recently reviewed by Trombettoni and coworkers [13].

Sulfonated cation-exchange resins are the most widely explored catalysts for the esterification/transesterification production of biodiesel. They are styrene-divinylbenzene copolymers that can be applied either as gels or as macroreticular resins. The first show low specific surface areas $\left(<10 \mathrm{~m}^{2} / \mathrm{g}\right)$ with low penetrability in the polymer network that is compensated by their swelling capability in appropriate solvents; the latter exhibit higher specific surface areas (50-100 $\left.\mathrm{m}^{2} / \mathrm{g}\right)$ and a quite permanent porous morphology with a wide pore size distribution that ranges from micro- $(<20 \AA)$ to meso- (20-500 $\AA$ ) and macro-pores (>500 $\AA$ ) [13]. Among the more investigated cation-exchange resins, the commercially available sulfonated resin Amberlyst- 15 has been used for promoting the esterification of many carboxylic acids, from acetic acid to long-chain fatty acids [13,14], resulting in good performances, especially as far as non-edible and waste cooking oils are concerned $[8,15]$.

Focus of the recent published researches are the investigation of the relationship between resin morphology and catalytic activity in FFA esterification, as well as the simulation of processes with conventional or unconventional reactors for a more efficient production of biodiesel. In particular, the process simulation plays a critical role in the frame of the biodiesel synthesis because of the thermodynamic chemical equilibrium that limits the conversion of the carboxylic acid in the esterification reaction with alcohols. To overcome this limitation, some researchers suggest the application of the reactive distillation technology and report the simulation results of the reaction-distillation steps by using different types of heterogeneous catalysts to achieve process intensification [16-22].

Process simulation and design require the knowledge of appropriate and simple kinetic models. Many works can be found in the literature, which report about kinetic models for fatty acid esterification with different heterogeneous catalysts, such as sulfated zirconia [23,24], Relite CFS [25], silica-supported tungstophosphoric acid [26], niobium oxide [12,27], or Amberlyst-46 [28]. As far as the use of Amberlyst-15 is concerned, simplified or more complex kinetic models can be found to describe the esterification of decanoic acid with methanol [16], nonanoic acid with ethanol [29], or oleic acid with methanol $[30,31]$. Furthermore, a kinetic/equilibrium model was also developed to explain the esterification of an artificially-acidified-soybean oil and a commercial mixture of waste fatty acids with high-acidity, both in the presence of Amberlyst-15 or Relite CFS [32].

In this work, the methanol-esterification of saturated fatty acids with different chain length (lauric, myristic, palmitic, and stearic acid), which were selected as the most representative saturated fatty acids that are contained in typical triglyceride feedstocks for biodiesel [33], has been investigated in a batch laboratory basket reactor both in the presence and in the absence of Amberlyst- 15 as the catalyst, in the $70-150{ }^{\circ} \mathrm{C}$ thermal range and at different molar ratios of the reactants. Even though unsaturated fatty acids, such as oleic, linoleic, and linolenic acid are also present at great extent in edible, non-edible, and waste oils [33], this work only deals with the above-reported saturated fatty acids to investigate at what extent the chain length of the acid could affect the kinetic behavior. The results obtained with Amberlyst- 15 were fitted, for the first time, through a ready-to-use simple pseudo-homogeneous reversible model that is suitable for process design and simulation. The results were compared with those that were obtained in a previous work [27] with niobium oxide as the catalyst to point out how different catalytic mechanisms could affect the reactivity of the fatty acids in the esterification reaction.

\section{Materials and Methods}

\subsection{Materials}

Sigma-Aldrich provided all of the reactants (purity 95-99.8\%) that were used without further purification. Sulfonated cation-exchange resin Amberlyst-15, in dry and hydrogen form, was also 
purchased from Sigma-Aldrich. The resin, a macro reticular styrene-divinylbenzene copolymer functionalized with strongly acidic sulfonic groups, has a concentration of active sites $\geq 4.7 \mathrm{eq} / \mathrm{kg}$, moisture $\leq 1.6 \%$, particle size of $600-800 \mu \mathrm{m}$, and is thermally stable up to $120{ }^{\circ} \mathrm{C}$.

\subsection{Experimental Apparatus and Procedures}

Figure 3 reports a scheme of the experimental apparatus. It is composed by a 300-mLstainless steel batch reactor (R) equipped with a stationary annular catalyst-basket-container (B), a magnetically-driven stirrer (S), a temperature (TI), and a pressure (PI) indicator. An electrical heating mantle $(\mathrm{H})$ allows for the reactor to be heated at the appropriate temperature of the test. The apparatus is equipped with a sampling line (SL) and a 100-mL stainless steel container for methanol addition (C), which is connected both to the reactor and to a nitrogen cylinder.

In a typical experimental test, the reactor was filled in with the fatty acid, the catalyst was positioned in the basket container and methanol at room temperature was introduced in the 100-ml container. The catalyst content was equal to $7 \mathrm{wt} . \%$ of the acid amount; this amount is consistent with that recommended by Ilgen after investigating the effect of the catalyst amount on conversion in a similar esterification process [28]. The reactor was preheated at an appropriate temperature before the injection of methanol, which occurred by applying a nitrogen overpressure to the methanol container. The value of the preheating temperature of the acid was fixed after preliminary tests to rapidly reach the scheduled reaction temperature (temperature-stabilization-time $<1 \mathrm{~min}$ ) as soon as it was mixed with methanol. The reaction was conducted in isothermal conditions and under a constant stirring rate of $700 \mathrm{rpm}$. Preliminary experiments at different rotational speeds pointed out that this stirring rate could guarantee that mass transfer limitations did not affect the measured kinetics [27]. Experiments were conducted at different temperatures $\left(70-150^{\circ} \mathrm{C}\right)$ and acid-to-alcohol molar ratios (1:1-1:2-1:5), both in the presence and in the absence of Amberlyst-15. A maximum limit of $110{ }^{\circ} \mathrm{C}$ was observed when Amberlyst-15 was employed to avoid the thermal degradation of the catalyst (Section 2.1), while tests of up to $150{ }^{\circ} \mathrm{C}$ were conducted for the uncatalyzed systems.

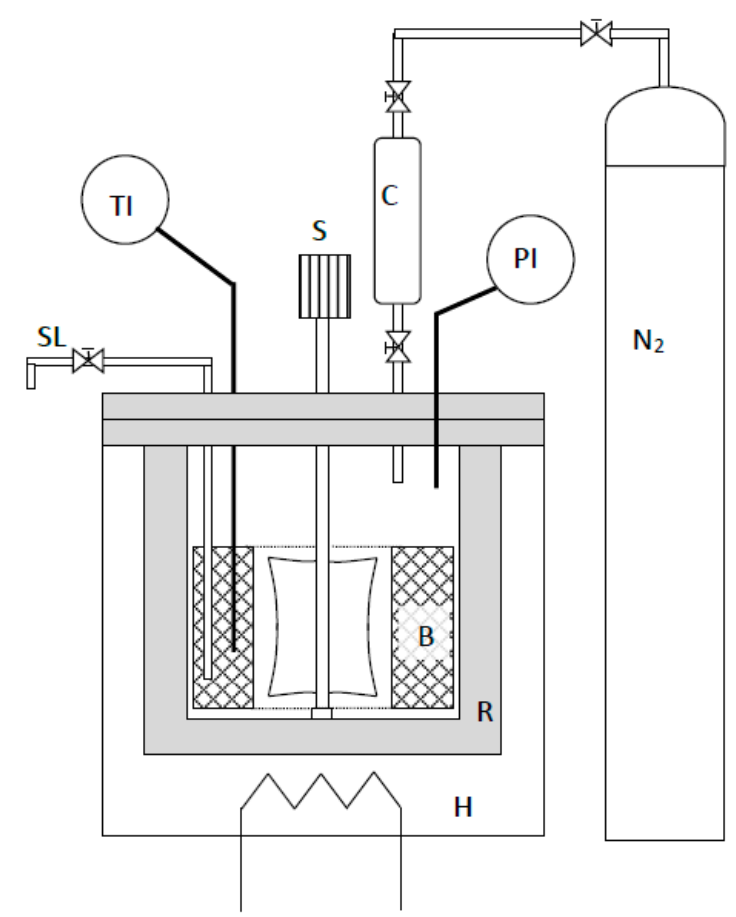

Figure 3. Experimental batch reactor. R: reactor; H: electrical heating mantle; B: annular stationary basket container; S: magnetically driven stirrer; TI: temperature indicator; PI: pressure indicator; C: stainless steel container for methanol addition; and, SL: sampling line. 
The reaction mixture was sampled at different times, the volatile components (water and methanol) were removed by heating each sample at $120^{\circ} \mathrm{C}$ for one hour in a ventilated oven to improve the repeatability of the analysis [32] and the acid fraction (residual acidity) was measured in duplicate according to standard carboxylic-acid-titration procedures $[12,24,25]$ with an error less than $\pm 2 \%$. The conversion of the fatty acid, $X_{A}$, versus time, $t$, was calculated from the variation of the residual acidity over time:

$$
X_{A}(t)=1-\frac{\text { residual acidity at time } t}{\text { initial acidity }(t=0)}
$$

\subsection{Kinetic Model}

Despite that many heterogeneous kinetic models were proposed in the literature $[12,16,25,28,31]$, the pseudo-homogeneous second-order reversible one is less complex and it requires smaller number of parameters to be estimated $[16,25]$. Furthermore, it is a ready-to-use simple approach that can be easily implemented in commercial process simulation software $[17,19,21,23,27]$. The following pseudo-homogeneous second-order equilibrium kinetic model [24] was used to fit the experimental data obtained in the batch reactor with Amberlyst-15:

$$
V \frac{d C_{A}}{d t}=r_{A} V=-k_{1} m_{c a t} C_{A} C_{B}+k_{2} m_{c a t} C_{E} C_{W}
$$

where $r_{A}$ is the reaction rate, $V$ is the volume of the pseudo-homogeneous reacting system, $m_{\text {cat }}$ is the amount of catalyst, $C_{A}, C_{B}, C_{E}, C_{W}$ are the molar concentrations of fatty acid $(A)$, methanol $(B)$, fatty acid methyl ester $(E)$, and water $(W)$, respectively. $k_{1}$ and $k_{2}$ are the forward and backward rate constants, which are referred to the catalyst loading as it generally occurs in pseudo-homogeneous models $[16,23,25,28,30,32]$. The conventional Arrhenius equation accounts for the variation of the rate constants with temperature, where $k_{1}=k_{1 \infty} \cdot \exp \left(-E_{1} / R T\right)$ and $k_{2}=k_{2 \infty} \cdot \exp \left(-E_{2} / R T\right)$, being $k_{1 \infty}$ and $k_{2 \infty}$ the pre-exponential factors and $E_{1}$ and $E_{2}$ the activation energies. According to the stoichiometry of the reaction $C_{A}=C_{A 0}\left(1-X_{A}\right), C_{B}=C_{A 0}\left(m-X_{A}\right), C_{E}=C_{W}=C_{A 0} X_{A}$, where $C_{A 0}$ is the initial concentration of the fatty acid and $m(=1,2,5)$ is the initial methanol/acid molar ratio, Equation (2) becomes:

$$
V \frac{d X_{A}}{d t}=k_{1} m_{c a t} C_{A 0}\left[\left(1-X_{A}\right)\left(m-X_{A}\right)-\frac{1}{K_{e q}} X_{A}^{2}\right]
$$

where $K_{e q}=k_{1} / k_{2}$ is the equilibrium constant.

The solution of Equation (3) leads to the following relation:

$$
\frac{\ln Y}{a_{2}}=\frac{1}{a_{2}} \ln \left[\left(\frac{2 a_{1} X_{A}-1-m-a_{2}}{2 a_{1} X_{A}-1-m+a_{2}}\right)\left(\frac{-1-m+a_{2}}{-1-m-a_{2}}\right)\right]=a_{3} k_{1} t
$$

where $a_{1}=\left(1-1 / K_{e q}\right), a_{2}=\left[(m+1)^{2}-4 a_{1} \cdot m\right]^{1 / 2}$, and $a_{3}=\left(C_{A 0} \cdot m_{c a t}\right) / V$. When $(\ln Y) / a_{2}$ is plotted versus $t$, it gives a straight line passing through the origin whose slope allows for $k_{1}$ to be determined. The backward rate constant, $k_{2}$, can be determined from the knowledge of $K_{e q}$, which can also be estimated from the experimental data. In fact, when $X_{A}$ is plotted versus time, it reaches an asymptotic value, $X_{\text {Aeq }}$, which corresponds to the equilibrium conversion, and allows for the equilibrium constant $K_{e q}$ to be calculated from the equation:

$$
K_{e q}=\frac{X_{A e q}^{2}}{\left(1-X_{A e q}\right)\left(m-X_{A e q}\right)}
$$

that is obtained assuming $d X_{A} / d t=0$ in Equation (3). 


\section{Results and Discussion}

Figure 4 reports, as an example, the experimental results for the esterification of palmitic acid with methanol to elucidate the methodological procedure that is described in Section 2.3. The residual acidity profiles versus time (Figure $4 a$ ) allowed for the conversion profiles (Figure $4 b$ ) to be determined according to Equation (1), which were used to calculate the $(\ln \gamma) / a_{2}$ (Equation (4)) and plot it versus $t$ (Figure 4c). The slope of the lines reported in Figure $4 \mathrm{c}$ allowed for the kinetic parameters at different temperatures to be estimated, as reported in Section 2.3. The pre-exponential factors and the activation energies of the forward and backward esterification reaction could be calculated, according to Arrhenius equation, from the slope and intercept of the semilogarithmic plot of the kinetic parameters versus $1 / \mathrm{T}$ (Figure $4 \mathrm{~d}$ ).

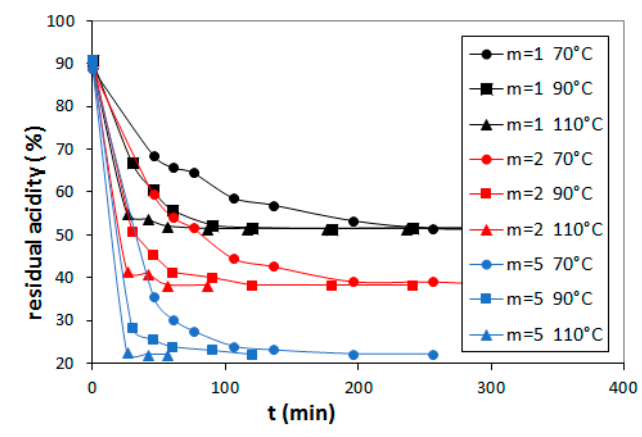

(a)

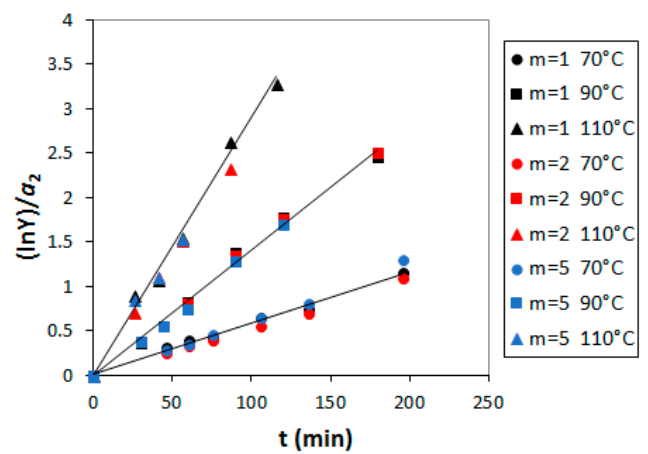

(c)

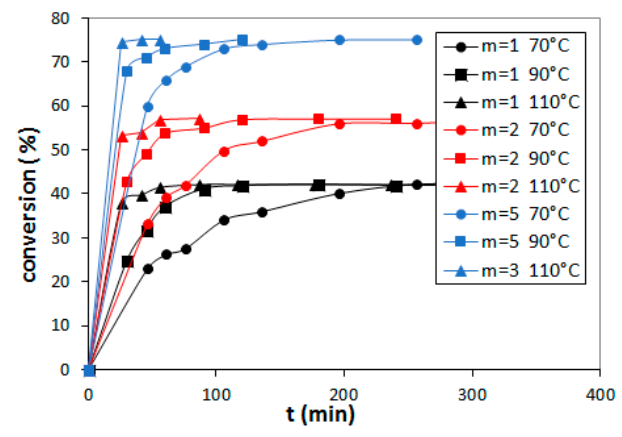

(b)

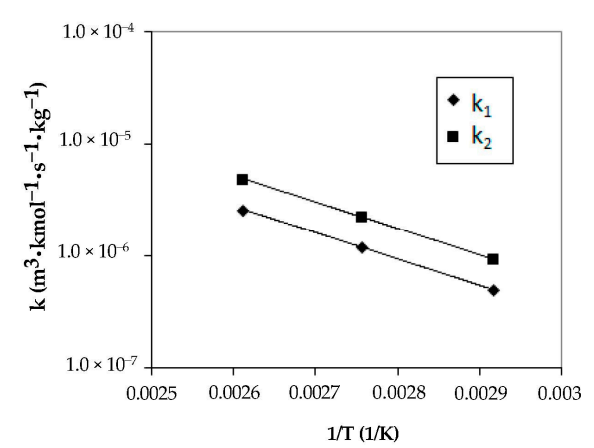

(d)

Figure 4. Evaluation of the kinetic parameters for the esterification of palmitic acid with methanol with Amberlyst-15: (a) residual acidity; (b) conversion profiles; (c) plot of $(\ln \gamma) / a_{2}$ versus time at different temperatures and methanol/acid molar ratios (m); and (d) forward and backward rate constant versus $1 / \mathrm{T}$.

Figure $4 \mathrm{~b}$ shows that the conversion increases versus time until equilibrium is achieved at steady state condition. At fixed methanol/acid molar ratio equilibrium does not depend on temperature, which points out that temperature does not affect the equilibrium conversion of the esterification reaction [34]. The same result was obtained for the other acid/alcohol systems: Figure 5 reports, for example, the results for the 1:1 esterification of lauric acid with methanol. On the other hand, equilibrium conversion can be increased by operating under an excess of alcohol, as reported in Figures $4 \mathrm{~b}$ and 6 . Figure 6 , in particular, reports the conversion profiles versus time at different acid:alcohol molar ratios for the uncatalyzed esterification of lauric acid at $150{ }^{\circ} \mathrm{C}$ and points out how the $50 \%$ equilibrium conversion that is obtained by operating at stoichiometric conditions of the reactants grows up to $86 \%$ by operating with a five-time methanol excess with respect to the fatty acid. The above-reported increase of conversion with the methanol/acid molar ratio (Figures $4 \mathrm{~b}$ and 6) occurs because the esterification of fatty acids and methanol is an equilibrium-limited reaction 
and operating under an excess of one of the reactants results in shifting the equilibrium towards the products.

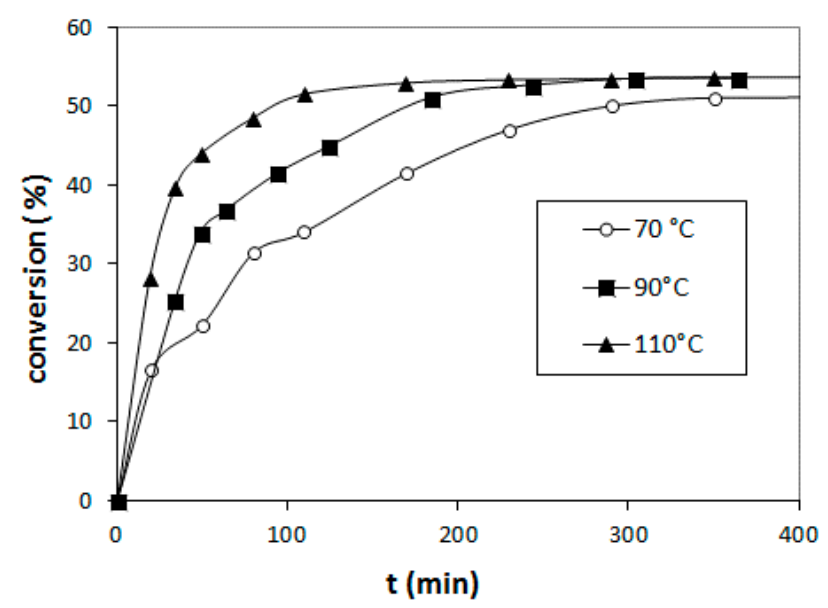

Figure 5. Conversion profiles versus time for the 1:1 esterification of lauric acid with methanol in the presence of Amberlyst-15 at different temperatures.

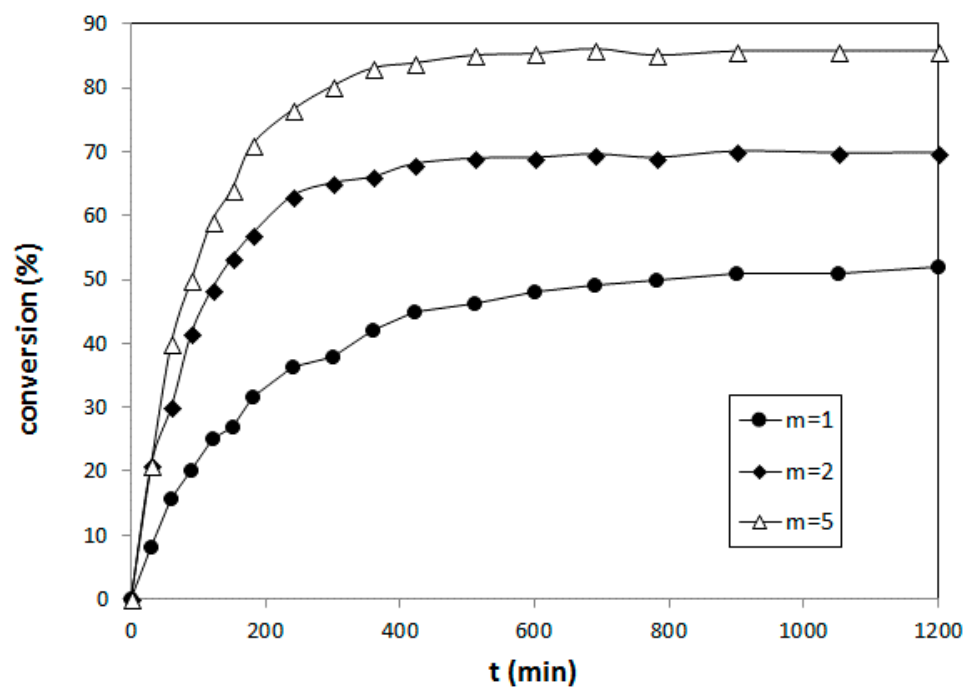

Figure 6. Conversion profiles versus time for the uncatalyzed esterification of lauric acid with methanol at $150^{\circ} \mathrm{C}$ and different acid:alcohol molar ratios.

Table 1 summarizes the kinetic parameters of the pseudo-homogeneous reversible model for the esterification reaction of lauric, myristic, palmitic, and stearic acid with methanol in the presence of Amberlyst-15, which provides a simple and ready-to-use tool for the design or simulation of biodiesel synthesis processes. Both the pre-exponential factors and the activation energies of the forward and backward esterification reactions with Amberlyst- 15 increase with the chain length of the fatty acid. Two opposite effects occur because if high pre-exponential factors would result in higher reactivity, high activation energies would imply a higher energetic barrier to reaction, so resulting in slower kinetics. It can be concluded that the fatty acids here investigated exhibit similar reactivity when Amberlyst-15 is employed for their esterification, as it is also reported in Figure 7 where the conversion profiles versus time for the 1:1 esterification of the different acids with methanol in the presence of Amberlyst- 15 is reported at $70^{\circ} \mathrm{C}$. The figure points out that the esterification of all fatty acids exhibits quite similar reaction rates. The slight difference between the activation energies of the forward and reverse kinetic constants (Table 1) implies that the esterification of fatty acids has a very small heat 
of reaction, which is coherent with the observed negligible role of temperature on the equilibrium conversion (Figures $4 \mathrm{~b}$ and 5 ).

Table 1. Kinetic parameters for the esterification of fatty acids with methanol.

\begin{tabular}{|c|c|c|c|c|c|}
\hline & Fatty Acid & $\frac{k_{1 \infty}}{\left(\mathrm{m}^{6} \cdot \mathrm{kmol}^{-1} \cdot \mathrm{s}^{-1} \cdot \mathrm{kg}^{-1}\right)}$ & $\mathrm{E}_{1}\left(\mathrm{~kJ} \cdot \mathrm{kmol}^{-1}\right)$ & $\frac{k_{2 \infty}}{\left(\mathrm{m}^{6} \cdot \mathrm{kmol}^{-1} \cdot \mathrm{s}^{-1} \cdot \mathrm{kg}^{-1}\right)}$ & $\mathrm{E}_{2}\left(\mathrm{~kJ} \cdot \mathrm{kmol}^{-1}\right)$ \\
\hline \multirow{4}{*}{$\begin{array}{l}\text { Amberlyst-15 } \\
\text { (this work) }\end{array}$} & Lauric (C12) & 0.164 & $36.5 \cdot 10^{3}$ & 0.134 & $36.6 \cdot 10^{3}$ \\
\hline & Myristic (C14) & 3.06 & $44.0 \cdot 10^{3}$ & 4.84 & $43.9 \cdot 10^{3}$ \\
\hline & Palmitic (C16) & 4.22 & $45.4 \cdot 10^{3}$ & 7.93 & $45.5 \cdot 10^{3}$ \\
\hline & Stearic (C18) & 20.0 & $50.1 \cdot 10^{3}$ & 41.1 & $49.9 \cdot 10^{3}$ \\
\hline \multirow{4}{*}{$\begin{array}{l}\text { Niobium oxide } \\
\text { [26] }\end{array}$} & Lauric (C12) & 16.8 & $55.7 \cdot 10^{3}$ & 19.7 & $55.0 \cdot 10^{3}$ \\
\hline & Myristic (C14) & 5.14 & $53.2 \cdot 10^{3}$ & 11.0 & $54.2 \cdot 10^{3}$ \\
\hline & Palmitic (C16) & 3.84 & $52.3 \cdot 10^{3}$ & 6.59 & $52.0 \cdot 10^{3}$ \\
\hline & Stearic (C18) & 3.61 & $52.2 \cdot 10^{3}$ & 4.72 & $52.2 \cdot 10^{3}$ \\
\hline
\end{tabular}

In Table 1, the trend of the pre-exponential factors and activation energies versus the fatty acid chain length obtained in this work is compared with that observed in a previous one [27] in the presence of niobium oxide as the catalysts and with the same pseudo-homogeneous reversible model. The two catalytic systems are also compared in Figure 8, where the conversion profiles versus time are reported for the esterification of lauric acid. The figure also reports the conversion profile of the uncatalyzed system; all of the data were obtained at $110^{\circ} \mathrm{C}$ with a 1:1 acid:methanol molar ratio in the same experimental apparatus and with the same procedure reported in Section 2.2. The first important result from the comparison of the two catalytic systems is that Amberlyst-15 has higher catalytic activity with respect to niobium oxide (Figure 8), which points out that employing Amberlyst-15 may be more promising as far as the industrial biodiesel synthesis through the hydro-esterification route is concerned. Second, the pre-exponential factors of the forward and reverse esterification reactions that were obtained in the presence of niobium oxide display the opposite trend versus the chain length of the acid with respect to those reported for Amberlyst-15 (Table 1). As far as the activation energies are concerned, their variation with the chain length is much less significant with respect to the data that were reported for Amberlyst-15. It can be concluded, then, that when niobium oxide is employed, the reactivity decreases with the increase of the chain length of the fatty acid, which means that the esterification of short-chain fatty acids is significantly faster than that of the long-chain ones. This is an interesting result. In fact, if the esterification of mixtures of different fatty acids for biodiesel synthesis has to be simulated, their composition may affect the final conversion performance in different ways, which depend on the employed catalyst. If niobium oxide is employed short-chain-fatty-acid-rich mixtures will be more reactive than the medium- to long-chain-rich ones; however, if Amberlyst-15 is employed, no significant differences would be observed. 


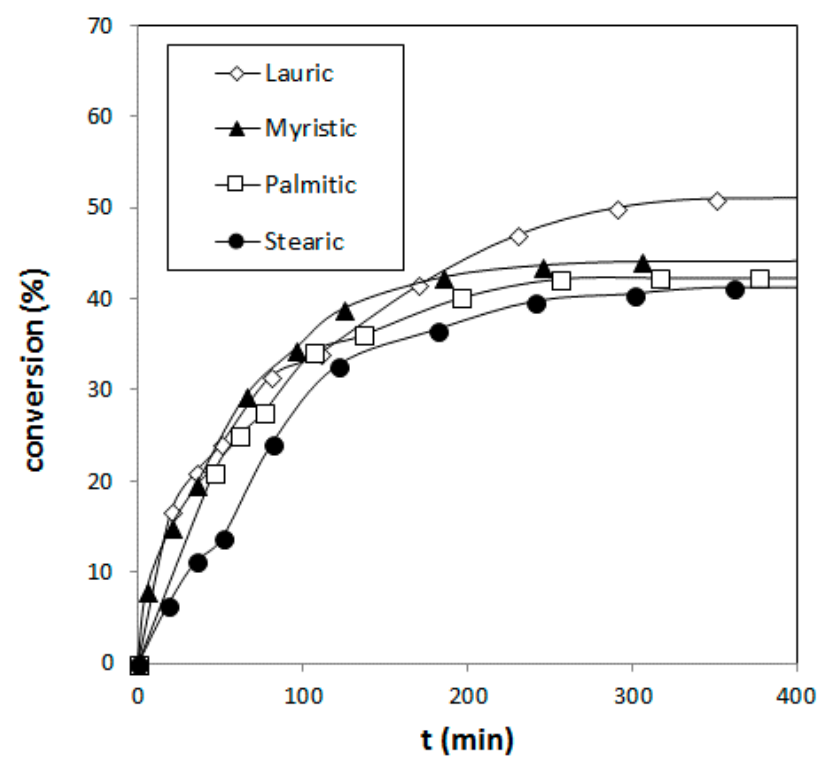

Figure 7. Conversion profiles versus time for the 1:1 esterification of different acids with methanol at $70{ }^{\circ} \mathrm{C}$ with Amberlyst- 15 .

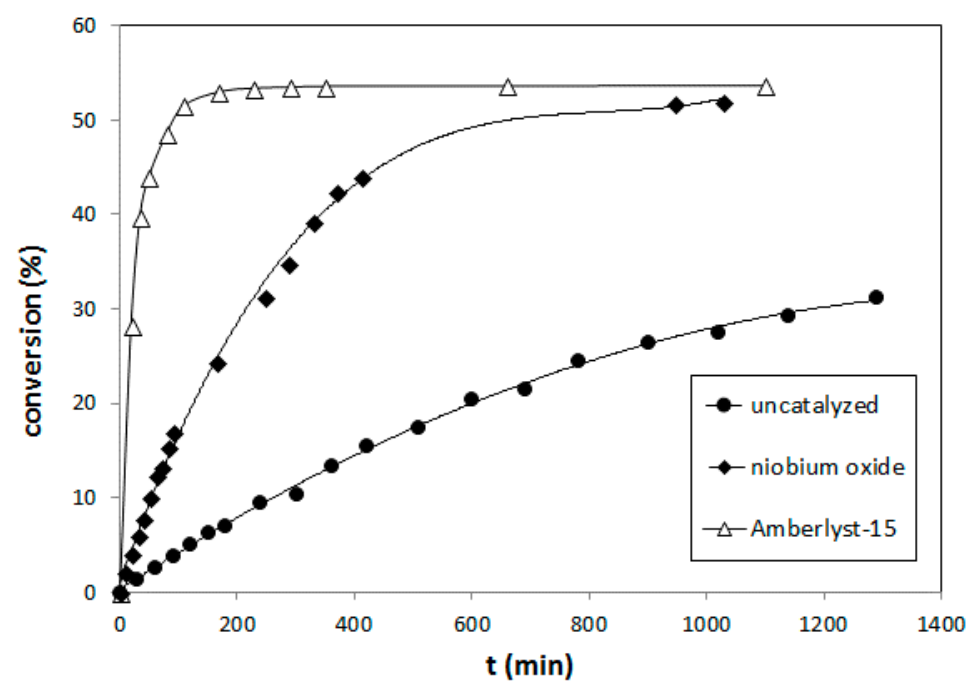

Figure 8. Conversion profiles versus time for the esterification of lauric acid with methanol at $110{ }^{\circ} \mathrm{C}$ and 1:1 acid:alcohol molar ratio-comparison of the uncatalyzed reaction with the niobium-oxide- and Amberlyst-15-catalyzed systems.

A plain and supported explanation of the different behavior of the two catalytic systems would require further experiments to elucidate the pathway of the catalytic mechanisms. Furthermore, more complex kinetic models could also give reason for the different trends of the pre-exponential factors versus the chain length. However, a tentative explanation of the reasons why the esterification of fatty acids in the presence of Amberlyst- 15 is not affected by the chain length of the fatty acids may be proposed based on the mechanism that is proposed by Kouzu and coworkers for sulfonated cation-exchange resins [8]. Contrary to inorganic materials, the polymer network of a resin is swelled by organic polar solvents, such as methanol, to an extent that depends on the crosslink density. The result is that a higher number of active sites is made accessible for the catalytic reaction. Furthermore, if it is supposed that the catalyst surface is covered by a layer of the swelling alcohol, the access of the fatty acid to the resin is controlled by the external mass transfer rate through this layer, which is 
not significantly affected by the small relative differences in molecular weight of the fatty acids here investigated. Since the active sites are completely covered by methanol, the reaction may "locally" occur with an excess of this reactant, regardless of the chain length of the acid, whose role in the mechanism becomes negligible. When niobium oxide is employed no layer of methanol is probably present on the catalyst surface and the reaction is controlled by the conventional mechanism of acid-catalyzed esterification, whose pathway consists in the nucleophilic reaction of the alcohol with the carboxylic group of the fatty acid, which has previously been protonated by the acid catalyst, and the reactivity is sterically affected by the alkyl chain length of the acid [12].

\section{Conclusions}

A pseudo-homogeneous reversible model for the esterification reaction of lauric, myristic, palmitic, and stearic acid with methanol in the presence of Amberlyst- 15 has been obtained from experimental results in a batch laboratory basket reactor. This model provides a simple and ready-to-use tool for the design or simulation of biodiesel synthesis processes. The results, when compared with those that were obtained in similar conditions with niobium oxide as the catalyst, indicate a higher catalytic activity of the Amberlyst- 15 without evidence of kinetic selectivity in the esterification of fatty acids in the C12-C18 range. The reactivity of the fatty acids in the presence of the resin appears almost independent on the length of the chain, which results from the compensation between the increase of both the pre-exponential factors and activation energies. The observed difference between the inorganic and the organic catalysts could be related to the different affinity of the methanol with the catalyst. This involves a stronger interaction with the Amberlist- 15 pore surface and a kinetic mass-transfer-controlled mechanism that hinders the access of the different fatty acids to the active sites of the resin in a similar way.

Author Contributions: G.G. funded the research. M.B. wrote the manuscript. Both authors equally contributed to conduction of the experiments and their interpretation.

Funding: This research received no external funding.

Conflicts of Interest: The authors declare no conflict of interest.

\section{References}

1. Barros, S.D.T.; Coelho, A.V.; Lachter, E.R.; San Gil, R.A.S.; Dahmouche, K.; Pais da Silva, M.I.; Souza, A.L.F. Esterification of lauric acid with butanol over mesoporous materials. Renew. Energy 2013, 50, 585-589. [CrossRef]

2. Lotero, E.; Liu, Y.; Lopez, D.E.; Suwannakarn, K.; Bruce, D.A.; Goodwin, J.G., Jr. Synthesis of biodiesel via acid catalysis. Ind. Eng. Chem. Res. 2005, 44, 5353-5363. [CrossRef]

3. Mowla, O.; Kennedy, E.; Stockenhuber, M. Hydroesterification of bio-oils over HZSM-5, BETA and Y zeolites. Clean Techn. Environ. Policy 2018, 20,727-738. [CrossRef]

4. Dos Santos, L.K.; Hatanaka, R.R.; De Oliveira, J.E.; Flumignan, D.L. Experimental factorial design on hydroesterification of waste cooking oil by subcritical conditions for biodiesel production. Renew. Energy 2017, 114, 574-580. [CrossRef]

5. Ge, J.C.; Yoon, S.K.; Choi, N.J. Using canola oil biodiesel as an alternative fuel in diesel engines: A review. Appl. Sci. (Basel) 2017, 7, 881. [CrossRef]

6. Atadashi, I.M.; Aroua, M.K.; Aziz, A.A. Biodiesel separation and purification: A review. Renew. Energy 2011, 36, 437-443. [CrossRef]

7. Corro, G.; Tellez, N.; Jimenez, T.; Tapia, A.; Banuelos, F.; Vazquez-Cuchillo, O. Biodiesel from waste frying oil. Two step process using acidified $\mathrm{SiO}_{2}$ for esterification step. Catal. Today 2011, 166, 116-122. [CrossRef]

8. Kouzu, M.; Nakagaito, A.; Hidaka, J.-S. Pre-esterification of FFA in plant oil transesterified into biodiesel with the help of solid acid catalysis of sulfonated cation-exchange resin. Appl. Catal. A Gen. 2011, 405, 36-44. [CrossRef]

9. Caetano, C.S.; Guerreiro, L.; Fonseca, I.M.; Ramos, A.M.; Vital, J.; Castanheiro, J.E. Esterification of fatty acids to biodiesel over polymers with sulfonic acid groups. Appl. Catal. A Gen. 2009, 359, 41-46. [CrossRef] 
10. Pourzolfaghar, H.; Abnisa, F.; Daud, W.M.A.W.; Aroua, M.K. A review of the enzymatic hydroesterification process for biodiesel production. Renew. Sustain. Energy Rev. 2016, 61, 245-257. [CrossRef]

11. Suwannakarn, K.; Lotero, E.; Ngaosuwan, K.; Goodwin, J.G., Jr. Simultaneous free fatty acid esterification and triglyceride transesterification using a solid acid catalyst with in situ removal of water and unreacted methanol. Ind. Eng. Chem. Res. 2009, 48, 2810-2818. [CrossRef]

12. De Araújo Gonaçalves, J.; Ramos, A.L.D.; Rocha, L.L.L.; Domingos, A.K.; Monteiro, R.S.; Peres, J.S.; Furtado, N.C.; Taft, C.A.; Aranda, D.A.G. Niobium oxide solid catalyst: Esterification of fatty acids and modeling for biodiesel production. J. Phys. Org. Chem. 2011, 24, 54-64. [CrossRef]

13. Trombettoni, V.; Lanari, D.; Prinsen, P.; Luque, R.; Marrocchi, A.; Vaccaro, L. Recent advances in sulfonated resin catalysts for efficient biodiesel and bio-derived additives production. Prog. Energ. Combust. Sci. 2018, 65, 136-162. [CrossRef]

14. Pal, R.; Sarkar, T.; Khasnobis, S. Amberlyst-15 in organic synthesis. Arkivoc 2012, 1, 570-609. [CrossRef]

15. Özbay, N.; Oktar, N.; Tapan, N.A. Esterification of free fatty acids in waste cooking oils (WCO): Role of ion-exchange resins. Fuel 2008, 87, 1789-1798. [CrossRef]

16. Steinigeweg, S.; Gmehling, J. Esterification of a fatty acid by reactive distillation. Ind. Eng. Chem. Res. 2003, 42, 3612-3619. [CrossRef]

17. Banchero, M.; Kusumaningtyas, R.D.; Gozzelino, G. Reactive distillation in the intensification of oleic acid esterification with methanol-A simulation case-study. J. Ind. Eng. Chem. 2014, 20, 4242-4249. [CrossRef]

18. Pérez-Cisneros, E.S.; Mena-Espino, X.; Rodríguez-López, V.; Sales-Cruz, M.; Viveros-García, T.; Lobo-Oehmichen, R. An integrated reactive distillation process for biodiesel production. Comput. Chem. Eng. 2016, 91, 233-246. [CrossRef]

19. Petchsoongsakul, N.; Ngaosuwan, K.; Kiatkittipong, W.; Aiouache, F.; Assabumrungrat, S. Process design of biodiesel production: Hybridization of ester-and transesterification in a single reactive distillation. Energy Convers. Manag. 2017, 153, 493-503. [CrossRef]

20. Kiss, A.A. Heat-integrated reactive distillation process for synthesis of fatty esters. Fuel Process. Technol. 2011, 92, 1288-1296. [CrossRef]

21. Machado, G.D.; Pellegrini Pessoa, F.L.; Castier, M.; Aranda, D.A.G.; Cabral, V.F.; Cardozo-Filho, L. Biodiesel production by esterification of hydrolyzed soybean oil with ethanol in reactive distillation columns: Simulation studies. Ind. Eng. Chem. Res. 2013, 52, 9461-9469. [CrossRef]

22. Cossio-Vargas, E.; Barroso-Munoz, F.O.; Hernandez, S.; Segovia-Hernandez, J.G.; Cano-Rodriguez, M.I. Thermally coupled distillation sequences: Steady state simulation of the esterification of fatty organic acids. Chem. Eng. Process. 2012, 62, 176-182. [CrossRef]

23. Omota, F.; Dimian, A.C.; Bliek, A. Fatty acid esterification by reactive distillation: Part 2-Kinetics-based design for sulphated zirconia catalysts. Chem. Eng. Sci. 2003, 58, 3175-3185. [CrossRef]

24. Rattanaphra, D.; Harvey, A.P.; Thanapimmetha, A.; Srinophakun, P. Kinetic of myristic acid esterification with methanol in the presence of triglycerides over sulphated zirconia. Renew. Energy 2011, 36, 2679-2686. [CrossRef]

25. Tesser, R.; Di Serio, M.; Guida, M.; Nastasi, M.; Santacesaria, E. Kinetics of oleic acid esterification with methanol in the presence of triglycerides. Ind. Eng. Chem. Res. 2005, 44, 7978-7982. [CrossRef]

26. Patel, A.; Brahmkhatri, V. Kinetic study of oleic acid esterification over 12-tungstophosphoric acid catalyst anchored to different mesoporous silica supports. Fuel Process. Technol. 2013, 113, 141-149. [CrossRef]

27. Banchero, M.; Gozzelino, G. $\mathrm{Nb}_{2} \mathrm{O}_{5}$-catalyzed kinetics of fatty acids esterification for reactive distillation process simulation. Chem. Eng. Res. Des. 2015, 100, 292-301. [CrossRef]

28. Ilgen, O. Investigation of reaction parameters, kinetics and mechanism of oleic acid esterification with methanol by using Amberlyst 46 as a catalyst. Fuel Process. Technol. 2014, 124, 134-139. [CrossRef]

29. Sharma, M.; Toor, A.P.; Wanchoo, R.K. Reaction kinetics of catalytic esterification of nonanoic acid with ethanol over Amberlyst 15. Int. J. Chem. React. Eng. 2014, 12, A38. [CrossRef]

30. Tesser, R.; Casale, L.; Verde, D.; Di Serio, M.; Santacesaria, E. Kinetics of free fatty acids esterification: Batch and loop reactor modeling. Chem. Eng. J. 2009, 154, 25-33. [CrossRef]

31. Ray, N.M.; Ray, A.K. Determination of adsorption and kinetic parameters for methyl oleate (biodiesel) esterification reaction catalyzed by Amberlyst 15 resin. Can. J. Chem. Eng. 2016, 94, 738-744. [CrossRef]

32. Tesser, R.; Casale, L.; Verde, D.; Di Serio, M.; Santacesaria, E. Kinetics and modeling of fatty acids esterification on acid exchange resins. Chem. Eng. J. 2010, 157, 539-550. [CrossRef] 
33. Lin, L.; Cunshan, Z.; Vittayapadung, S.; Xiangqian, S.; Mingdong, D. Opportunities and challenges for biodiesel fuel. Appl. Energy 2011, 88, 1020-1031. [CrossRef]

34. Rani, K.N.P.; Neeharika, T.S.V.R.; Kumar, T.P.; Satyavathy, B.; Sailu, C. Kinetics of non-catalytic esterification of free fatty acids present in Jatropha oil. J. Oleo Sci. 2016, 65, 441-445. [CrossRef] [PubMed] 